\title{
Effect of steam explosion of oil palm frond and empty fruit bunch on nutrient composition and ruminal fermentation characteristics
}

\author{
Hao $\mathrm{Wu}^{1} \cdot$ Zhenming Zhou ${ }^{1} \cdot$ Yuanlong Yang ${ }^{1} \cdot$ Qingxiang Meng ${ }^{1}$ \\ Received: 10 February 2019 / Accepted: 16 October 2019 / Published online: 9 November 2019 \\ (C) The Author(s) 2019
}

\begin{abstract}
In this study, we evaluated the effect of steam explosion of oil palm frond (OPF) and oil palm empty fruit bunch (EFB) on nutrient composition and ruminal fermentation characteristics in vitro. The results showed that steam explosion decreased NDF $(P<$ $0.01), \operatorname{ADF}(P<0.01)$, and hemicellulose content $(P<0.01)$ in OPF and EFB. Steam explosion improved the effective energy value of OPF and EFB. In vitro fermentation results revealed that 72 -h gas production capacity of OPF and EFB increased by 12.60 and $85.06 \%(P<0.01)$, respectively, after steam explosion. Steam explosion had a tendency to improve the concentration of total volatile fatty acids (TVFA) $(P=0.082)$. In conclusion, steam explosion of OPF and EFB reduced NDF, ADF, and hemicellulose content and increased gas production and TVFA concentration.
\end{abstract}

Keywords Steam explosion $\cdot$ Oil palm by-products $\cdot$ Nutrient composition $\cdot$ Gas production $\cdot$ Ruminal fermentation in vitro

\section{Introduction}

Oil palm (Elaeis guineensis), which is native to Western Africa, grows in tropical regions and is considered to be the most important agricultural crop in China and Southeast Asia. As palm oil production increases, oil palm by-products such as empty fruit bunch (EFB), palm kernel shell (PKS), oil palm trunk (OPT), and oil palm frond (OPF) grow exponentially. Oil palm constitutes a renewable cellulose source; however, due to local heat and highly perishable by-products, the disposal of oil palm residues represents a significant concern for the oil palm industry. Currently, by-products of oil palm are incinerated or used as organic fertilizer, thereby leading to increased environmental pollution and costs (Abnisa et al. 2013). Therefore, it is important to find applications for oil palm by-products to improve their economic value. Steam explosion is commonly used in the biomass resources because most of the hemicellulose can be extracted from the exploded materials (Martin-Sampedro et al. 2012). Moreover, steam

Zhenming Zhou

zhouzm@cau.edu.cn

1 State Key Laboratory of Animal Nutrition, College of Animal Science and Technology, China Agricultural University, Beijing 100193, China explosion enhances the accessibility of bacteria and enzymes to the exploded materials. Steam explosion of oil palm byproducts may potentially improve their digestibility. Most studies on steam explosion of biomass resources have focused on industrial applications such as pulping, saccharification, and fermentation. There is limited information on steamexploded products and their digestion in ruminant animals. Therefore, this study assessed the effects of steam-exploded oil palm by-products on chemical nutrient composition and ruminal fermentation characteristics.

\section{Materials and methods}

\section{Animals and diets}

All animal experiments were approved by the Animal Welfare and Ethical Committee of China Agricultural University (Permit No. DK18030608) and performed in accordance with the Regulations for the Administration of Affairs Concerning Experimental Animals (The State Science and Technology Commission of P. R. China, 1988). Ruminal fluid was collected and pooled from three Simmental $\times$ Fuzhou crossbred steers (average body weight is $400 \mathrm{~kg}$ ), each fitted with a permanent rumen cannula. The ingredients and nutrient composition of the experimental diets are shown in Table 1 . Ruminal fluid inoculum was obtained prior to the morning 
Table 1 Ingredients and chemical composition of the diet

\begin{tabular}{ll}
\hline Items & $\%, \mathrm{DM}$ \\
\hline Ingredients & \\
Steam-flaked corn & 34.10 \\
Soybean curb residue & 12.60 \\
Brewer's grains & 8.10 \\
Maize silage & 39.00 \\
Chinese wild rye & 5.00 \\
Sodium bicarbonate & 0.30 \\
Salt & 0.50 \\
Premix ${ }^{1}$ & 0.50 \\
Chemical composition & \\
ME(MJ/kg) & 6.35 \\
OM & 93.91 \\
CP & 13.02 \\
ADF & 29.27 \\
NDF & 53.86 \\
Ca & 0.61 \\
P & 0.29 \\
\hline
\end{tabular}

$M E$ metabolic energy, $O M$ organic matter, $C P$ crude protein, $A D F$ acid detergent fiber, $N D F$ neutral detergent fiber

${ }^{1}$ Premix contained the following (IU per kg): vitamin A, 3000; vitamin $\mathrm{D}_{3}$, 1200; vitamin E, 10; (mg): Cu, 8; Fe, 50; Zn, 30; Mn, 40; Co, 0.1; Se, $0.2 ; \mathrm{I}, 0.5$

feeding. Ruminal contents were passed through four layers of cheesecloth, pooled, and sent to the laboratory.

\section{Chemical analysis and FE-SEM analysis}

We obtained OPF and EFB samples from Hainan, China, and randomly divided them into two parts. One part was sun-dried at ambient temperature for a several days. The samples were subsequently ground to a $10 \sim 20-\mathrm{mm}$ particle size using a knife mill, and rubbed. The other part was subjected to steam explosion after soaking in water for $24 \mathrm{~h}$. Steam pressure was 1.5 $\mathrm{MPa}$ and the retention time was $1 \mathrm{~min}$. The treatment was conducted by using a specially designed steam explosion vessel at the pilot plant of the Beef Cattle Experimental Station of China Agricultural University. Steam explosion was conducted three times. Each batch of about $3 \mathrm{~kg}$ of OPF or EFB was put into the steam chamber. The steam was adjusted to the desired pressure 1.5 MPa. Counting of retention time $1 \mathrm{~min}$ for each run was started when steam reached to the target pressure. Steam was suddenly released at the end of each treatment to give the explosion effect. The treated OPF or EFB was collected, dried, and ground as described above.

The chemical composition of OPF and EFB (Table 2) was determined following AOAC methods (2012). Crude protein (CP) was determined by measuring nitrogen content (FP-528,
Leco, St. Joseph, MO, USA). Crude fiber (CF), neutral detergent fiber (NDF), acid detergent fiber (ADF), and lignin (ADL) were measured using a fiber analyzer (A220, Ankom Technology, Macedon, NY, USA). Ether extract (EE) was analyzed by an extraction system (Ankom XT10 extractor, Ankom Technology, Macedon, NY, USA). Calcium was determined by atomic absorption spectrophotometry (WFX320 , Braic, Beijing, China), and phosphorus was determined by UV spectrophotometry (UVVIS 8500, Tianmei Scientific Instrument Co., Ltd., Shanghai, China). Based on the nutrient content of the feeds, we used the energy value prediction formula of INRA $(1978,1988)$ to calculate the effective energy. The formulas included GE $(\mathrm{Mcal} / \mathrm{kg})=17.3+0.0617 \times$ $\mathrm{CP}+0.2193 \times \mathrm{EE}+0.0387 \times \mathrm{CF}-0.1867 \times$ ash $+0.19 ; \mathrm{DE}$ $(\mathrm{Mcal} / \mathrm{kg})=\mathrm{GE} \times \mathrm{Ed} / 100 ; \mathrm{ME}(\mathrm{Mcal} / \mathrm{kg})=\mathrm{DE} \times \mathrm{ME} / \mathrm{DE} ;$ $\mathrm{NE}_{\mathrm{m}}(\mathrm{Mcal} / \mathrm{kg})=\mathrm{ME} \times \mathrm{km} ;$ and $\mathrm{NE}_{1}(\mathrm{Mcal} / \mathrm{kg})=\mathrm{ME} \times \mathrm{kl}$; $\mathrm{NE}_{\mathrm{g}}(\mathrm{Mcal} / \mathrm{kg})=\mathrm{ME} \times \mathrm{kg}$, where GE is gross energy, $\mathrm{DE}$ is digestible energy, $\mathrm{ME}$ is metabolizable energy, $\mathrm{NE}_{\mathrm{m}}$ is the net energy for maintenance, $\mathrm{NE}_{1}$ is the net energy for lactation, and $\mathrm{NE}_{\mathrm{g}}$ is the net energy for weight gain.

SEM analysis was performed with a MERLIN FE-SEM (Carl Zeiss Microscopy, Oberkochen, Germany). The samples were AU-coated by sputtering method using a JEOL JFC1600 coater sputter (Redding, USA).

\section{In vitro gas production and fermentation parameters}

Incubations were conducted anaerobically using the gas production method reported by Menke et al. (1979). Gas production was repeated three times for each group. Briefly, ruminal fluid filtrates were pooled into an anaerobic buffer solution under a constant flow of $\mathrm{O}_{2}$ that was free of $\mathrm{CO}_{2}$ (ruminal fluid-to-buffer ratio 1:2). Using an automatic pump, the inoculated culture medium were transferred into glass syringes (HFT000025, Häberle Maschinenfabrik GmbH, Germany), which were previously warmed to $39^{\circ} \mathrm{C}$. The syringes were incubated in a shaking water bath at $39{ }^{\circ} \mathrm{C}$. Blank syringes containing only inoculated culture medium with no substrate were simultaneously incubated. There were three blank syringes per group. Gas production in each syringe was measured at $1,2,3,4,5,6,8,10,12,16,20,24,28,32,36,40,48$, and $72 \mathrm{~h}$. To terminate the fermentation, the syringes were placed in ice water. To assess fermentation, duplicate syringes were incubated as described above; however, the incubation was terminated at $24 \mathrm{~h}$. Aliquots of the fermentation fluid were sampled for $\mathrm{pH}$ measurement $(10 \mathrm{~mL})$ and for VFA and ammonia $\mathrm{N}$ determination $(10 \mathrm{~mL})$ prior to centrifugation at $8000 \mathrm{~g}$ for $15 \mathrm{~min}$ at $4{ }^{\circ} \mathrm{C}$. The dynamics of gas production were computed by the nonlinear equation (Orskov and Mcdonald 1979) $y=b \times\left(1-e^{-c t}\right)$, where $y$ is the volume of gas produced at time $t, b$ is the potential gas production $(\mathrm{mL} / \mathrm{g}$ $\mathrm{DM}$ ), and $c$ is the fractional rate of gas production. 
Table 2 Effect of steam explosion on nutrient composition of oil palm frond (OPF) and oil palm empty fruit bunch (EFB) (\%, DM)

\begin{tabular}{|c|c|c|c|c|c|c|c|c|}
\hline \multirow[t]{2}{*}{ Item } & \multicolumn{2}{|l|}{ OPF } & \multicolumn{2}{|l|}{ EFB } & \multirow[t]{2}{*}{ SEM } & \multicolumn{3}{|l|}{$\mathrm{P}$} \\
\hline & Control & Steam explosion & Control & Steam explosion & & S & $\mathrm{T}$ & $\mathrm{S} \times \mathrm{T}$ \\
\hline $\mathrm{DM}$ & $97.57^{\mathrm{b}}$ & $97.69^{\mathrm{a}}$ & $92.55^{\mathrm{d}}$ & $93.32^{\mathrm{c}}$ & 0.024 & $<0.001$ & $<0.001$ & $<0.001$ \\
\hline $\mathrm{CP}$ & $1.98^{\mathrm{b}}$ & $1.95^{\mathrm{b}}$ & $4.54^{\mathrm{a}}$ & $4.72^{\mathrm{a}}$ & 0.098 & $<0.001$ & 0.455 & 0.321 \\
\hline $\mathrm{EE}$ & $2.77^{\mathrm{c}}$ & $1.33^{\mathrm{d}}$ & $4.62^{\mathrm{b}}$ & $8.22^{\mathrm{a}}$ & 0.119 & $<0.001$ & $<0.001$ & $<0.001$ \\
\hline $\mathrm{NDF}$ & $73.26^{\mathrm{b}}$ & $65.69^{c}$ & $80.86^{\mathrm{a}}$ & $72.12^{\mathrm{b}}$ & 0.424 & $<0.001$ & $<0.001$ & 0.208 \\
\hline $\mathrm{ADF}$ & $49.22^{\mathrm{c}}$ & $47.46^{\mathrm{d}}$ & $56.00^{\mathrm{a}}$ & $53.89^{\mathrm{b}}$ & 0.434 & $<0.001$ & 0.002 & 0.692 \\
\hline $\mathrm{ADL}$ & $9.72^{\mathrm{c}}$ & $9.45^{\mathrm{c}}$ & $16.21^{\mathrm{a}}$ & $15.88^{\mathrm{b}}$ & 0.100 & $<0.001$ & 0.016 & 0.768 \\
\hline Ash & $3.31^{\mathrm{d}}$ & $4.19^{c}$ & $5.40^{\mathrm{a}}$ & $5.12^{\mathrm{b}}$ & 0.018 & $<0.001$ & $<0.001$ & $<0.001$ \\
\hline Hemicellulose & $22.81^{\mathrm{b}}$ & $18.81^{\mathrm{c}}$ & $24.39^{\mathrm{a}}$ & $18.76^{\mathrm{c}}$ & 0.435 & 0.116 & $<0.001$ & 0.100 \\
\hline Cellulose & $38.61^{\mathrm{a}}$ & $34.38^{\mathrm{b}}$ & $38.35^{\mathrm{a}}$ & $35.99^{\mathrm{b}}$ & 0.511 & 0.223 & $<0.001$ & 0.103 \\
\hline
\end{tabular}

$\mathrm{S}$ represents the oil-palm by product, $\mathrm{T}$ represents steam explosion, and $\mathrm{S} \times \mathrm{T}$ represents the interaction effect between $\mathrm{S}$ and $\mathrm{T}$. In the same row, values with different letters represent significant differences $(P<0.05)$

$D M$ dry matter, $C P$ crude protein, $E E$ ether extract, $N D F$ neutral detergent fiber, $A D F$ acid detergent fiber, $A D L$ acid detergent lignin

\section{Statistical analysis}

We analyzed the data using SAS (version 9.4; SAS Institute, Cary, NC, USA) software. Nutrient composition, gas production, and in vitro fermentation characteristics were analyzed using the MIXED procedure with the following model $y_{i j}=\mu$ $+\alpha_{i}+\beta_{j}+\alpha_{i} \times \beta_{j}+e_{i j}$, where $y_{i j}$ is the dependent variable, $\mu$ is the overall mean, $\alpha_{i}$ is the fixed effect of steam explosion, $\beta_{j}$ is the fixed effect of oil palm by-product, $\alpha_{i} \times \beta_{j}$ is the interaction between treatment and oil palm by-product, and $e_{i j}$ is the random residual error. Duncan significant difference test was performed to determine differences among means. Statistical significance was set at $P \leq 0.05$.

\section{Results}

\section{Effect of steam explosion on the nutritional composition of OPF and EFP}

The nutrient composition of OPF and EFP is shown in Table 2. Steam explosion reduced NDF and ADF content $(P$ $<0.01)$; however, the interaction between steam explosion and oil palm by-product type was not significant $(P>0.05)$. In OPF and EFB, NDF content decreased from 73.26 and $80.86 \%$ to 65.69 and $72.12 \%$, respectively, and ADF content decreased from 49.22 and $56.00 \%$ to 47.46 and $53.89 \%$, respectively. Steam explosion also reduces cellulose and hemicellulose content in OPF and EFB $(P<0.01)$. Following steam explosion, hemicellulose content decreased from 22.81 to $18.80 \%$ in OPF and from 24.39 to $18.80 \%$ in EFP. Cellulose content was reduced from 38.61 to $34.38 \%$ in OPF and from 38.35 to $35.99 \%$ in EFB. Additionally, steam explosion increased EE content in EFB $(P<0.01)$ and reduced EE content in OPF $(P<0.01)$. Steam explosion and oil palm byproducts had significant interaction effects $(P<0.01)$. There were no significant differences in $\mathrm{CP}$ between control and treatment (steam explosion) and no significant interaction effects among palm by-products types $(P>0.05)$.

\section{Effect of steam explosion on the effective energy value of OPF and EFB}

The prediction of energy value is an important aspect of the evaluation of the nutritional value of ruminant feed. Table 3 shows the changes in GE, DE, ME, $\mathrm{NE}_{\mathrm{m}}, \mathrm{NE}_{1}$, and $\mathrm{NE}_{\mathrm{g}}$ following steam explosion of OPF and EFB. Steam explosion numerically increased the effective energy value of OPF and EFB. Following steam explosion, $\mathrm{ME}, \mathrm{NE}_{\mathrm{m}}, \mathrm{NE}_{\mathrm{l}}$, and $\mathrm{NEg}$ increased by $1.26,1.90,1.99$, and $5.26 \%$, respectively, in OPF and by 13.52, 14.99, 14.99, and 24.06, respectively, in EFB.

\section{Effect of steam explosion on the morphologies of OPF and EFB}

Changes of morphologies of the steam exploded materials (A and $\mathrm{C}$ ) in comparison with the original materials (B and $\mathrm{D})$ are presented in Fig. 1. In general, the regular shape of the sample changed into spherical and round shaped particles after steam explosion. Moreover, there were more free granules sticking to the surface.

\section{Effect of steam explosion on gas production and fermentation in vitro}

Table 4 shows the effect of steam explosion of OPF and EFB on in vitro gas production. The 72-h gas production capacity of OPF and EFB increased by $12.60 \%$ and $85.06 \%(P<0.01)$, 
Table 3 Effect of steam explosion on energy values of oil palm frond (OPF) and oil palm empty fruit bunch (EFB)

\begin{tabular}{llllll}
\hline Item & \multicolumn{2}{l}{ OPF } & \multicolumn{2}{l}{ EFB } \\
\cline { 2 - 3 } \cline { 5 - 6 } & Control & Steam explosion & & Control & Steam explosion \\
\hline $\mathrm{GE}(\mathrm{MJ} / \mathrm{kg})$ & 19.63 & 19.09 & 20.03 & 20.81 \\
$\mathrm{DE}(\mathrm{MJ} / \mathrm{kg})$ & 8.90 & 9.00 & 7.27 & 8.24 \\
$\mathrm{ME}(\mathrm{MJ} / \mathrm{kg})$ & 7.17 & 7.26 & 5.77 & 6.55 \\
$\mathrm{NE}$ & $(\mathrm{MJ} / \mathrm{kg})$ & 4.73 & 4.82 & 3.67 & 4.22 \\
$\mathrm{NE}_{1}(\mathrm{MJ} / \mathrm{kg})$ & 3.95 & 4.03 & 3.07 & 3.52 \\
$\mathrm{NE}_{\mathrm{g}}(\mathrm{MJ} / \mathrm{kg})$ & 2.09 & 2.20 & 1.33 & 1.65 \\
\hline
\end{tabular}

$G E$ gross energy, $D E$ digestible energy, $M E$ metabolic energy, $N E_{m}$ net energy for maintenance, $N E_{l}$ net energy for lactation, $N E_{g}$ net energy for weight gain

respectively, after steam explosion. There was a significant interaction between steam explosion and oil palm byproducts $(P<0.01)$. The predicted maximum gas production volume increased from 99.50 to $107.75 \mathrm{~mL}$ in OPF $(+8.29 \%)$ and from 33.24 to $62.06 \mathrm{~mL}$ in $\mathrm{EFB}(+86.70 \%, P<0.01)$. There was no significant effect on gas production rate $(P>$ 0.05 ) among oil palm by-products after steam explosion.

Table 5 shows the effect of steam explosion on the fermentation parameters of OPF and EFB following a 24-h in vitro digestion. It was shown that steam explosion had no significant effects both on $\mathrm{NH}_{3}-\mathrm{N}$ concentration and $\mathrm{pH}$ value $(P>$ $0.05)$. Though steam explosion had a tendency to increase the concentration of total volatile fatty acids (TVFA) $(P=0.082)$ and the molar proportion of valeric acid $(P=0.074)$, there was no treatment effect on other individual VFA $(P>0.05)$ in OPF and EFB. However, there was interaction between by-product sources and treatments on individual VFAs. Specifically, molar proportion of propionate acid was increased by steam explosion, while isobutyrate acid and isovaleric acid were decreased significantly only in EFB.

\section{Discussion}

OPF and EFB consist mainly of cellulose, hemicellulose, and lignin. Steam explosion may dissolve most hemicellulose in raw materials and degrade a small amount of cellulose and lignin, which will contribute to improved enzymatic accessibility (Silveira et al. 2018). The collapse surface morphology was observed for OPF and EFB, which was probably due to the substantial depolymerization and decreased solubilization of lignin in steam explosion. During steam explosion, hemicellulose is hydrolyzed into monosaccharides and oligosaccharides, the crystallinity and polymerization of cellulose are reduced, and lignin is degraded into phenolic acids (Carvalho et al. 2018; Tanpichai et al. 2019). Additionally, under high temperature conditions, acetyl cellulose yields acetic acid, which accelerates the degradation of cellulose and hemicellulose (Carvalheiro et al. 2008). These factors eventually decrease the content of cellulose and hemicellulose in oil palm by-products. Our results were consistent with those obtained by others (Chang et al. 2012), who reported that cellulose, hemicellulose, and lignin were reduced by $8.47 \%, 50.45 \%$, and $36.65 \%$, respectively, in steam-exploded corn straw. As a result of reducing crude fiber but crude protein content of the materials, crude fat was more likely concentrated other than increased by steam explosion in EFB. Chaji et al. (2010), who used in vitro gas production technique to predict the energy value of bagasse, reported that ME increased by $44.43 \%$ after steam explosion treatment, which was the same with our findings. The effective energy values of the samples were predicted base on the chemical compositions using the equations of
Fig. 1 The surface morphology of all the samples performed by SEM. In untreated empty fruit bunch (EFB), the straw itself is surrounded by a sheath (a), and SEM scan of EFB surface shows the "globular" deposits characteristic (b). In untreated oil, palm frond (OPF) (c) and steam explosion causes partially separated fiber and a surface layer with debris and droplets (d)
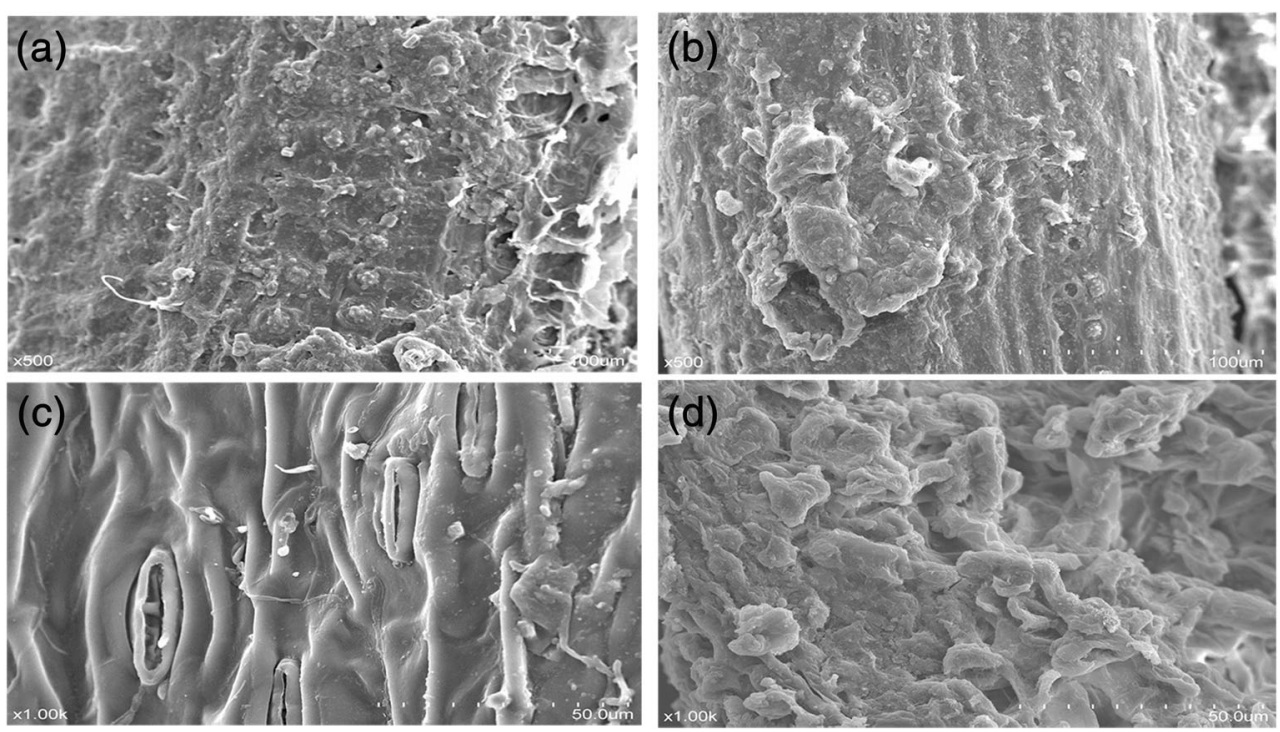
Table 4 Effect of steam explosion on the 72-h gas production (GP) of oil palm frond (OPF) and oil palm empty fruit bunch (EFB)

\begin{tabular}{|c|c|c|c|c|c|c|c|c|}
\hline \multirow[t]{2}{*}{ Items } & \multicolumn{2}{|l|}{ OPF } & \multicolumn{2}{|l|}{ EFB } & \multirow[t]{2}{*}{ SEM } & \multicolumn{3}{|l|}{$\mathrm{P}$} \\
\hline & Control & Steam explosion & Control & Steam explosion & & S & $\mathrm{T}$ & $\mathrm{S} \times \mathrm{T}$ \\
\hline 72 h GP (mL) & $105.13 b$ & $118.38 \mathrm{a}$ & $35.55 \mathrm{~d}$ & $65.79 \mathrm{c}$ & 2.002 & $<0.001$ & $<0.001$ & 0.005 \\
\hline Predicted maximum GP (mL) & $99.50 \mathrm{~b}$ & $107.75 \mathrm{a}$ & $33.24 \mathrm{~d}$ & $62.06 \mathrm{c}$ & 1.651 & $<0.001$ & $<0.001$ & $<0.001$ \\
\hline Rate of GP $\left(h^{-1}\right)$ & $0.14 \mathrm{a}$ & $0.14 \mathrm{a}$ & $0.10 \mathrm{~b}$ & $0.09 b$ & 0.007 & $<0.001$ & 0.274 & 0.147 \\
\hline
\end{tabular}

$\mathrm{S}$ represents the oil-palm by product, $\mathrm{T}$ represents steam explosion, and $\mathrm{S} \times \mathrm{T}$ represents the interaction effect between $\mathrm{S}$ and $\mathrm{T}$. In the same row, values with different letters represent significant differences $(P<0.05)$

INRA, where the EE content made a major contribution to the results. Take EFB as example, steam explosion increased the $\mathrm{EE}$, and decreased the CF content of the material, which could make the calculated GE value higher than untreated sample.

Ruminal bacteria perform a number of metabolic functions that are essential for animal physiology and performance, including nutrient metabolism, polysaccharide degradation, and fermentation (Welkie et al. 2010; Derakhshani et al. 2017). Steam explosion significantly improved gas production from OPF and EFB, consistent with previous reports (Liu et al. 1999; Chaji et al. 2010). Chaji et al. (2010) reported that the 72 -h maximum gas production of bagasse increased from 107.6 to $118.5 \mathrm{~mL}$ (+ $10.13 \%$ ) following steam explosion. Similarly, Liu et al. (1999) observed that steam explosion increased total gas production of wheat straw by $27 \%$. There is a linear and positive relationship between soluble carbohydrate content and feed gas production (Liu and Orskov 2000). Castro et al. (1994) concluded that in vitro wheat straw gas production was significantly higher in the steam-exploded group than in the control group $(49.8 \mathrm{~mL}$ vs. $33.2 \mathrm{~mL}$ ) (Castro et al. 1994). The increase in gas production may be attributed to an increase in soluble carbohydrate content in the feed. Steam explosion could increase soluble oligosaccharides, which served as an energy source for microorganisms, represented a high degradation of hemicellulose in the feed (Sabiha-Hanim et al. 2015). Moreover, steam explosion may denature the cuticle structure of the plant, thereby reducing the crystallinity and polymerization of cellulose and improving the accessibility of cellulase to the feed. Kim et al. (2005) reported that the molecular percentages of propionate increased in steamexploded rice straw compared to untreated rice straw, which is similar to EFB treatment (Kim et al. 2005). In general, increased propionate in the rumen accompanies increase in feed efficiency because propionate is gluconeogenic in animal tissues and much of it is converted to energy for animal growth. The increase in gas production indicated that nutrients in the feed are better utilized by microorganisms; therefore, steam explosion may improve the nutritional value of OPF and EFB.

Ruminal bacterial adherence plays important roles in feed digestion. Minato et al. (1993) reported that microbial populations associated with feed particles are estimated to be responsible for $91 \%$ of glucanase, $88 \%$ of xylanase, $70 \%$ of amylase, and $75 \%$ of protease activity (Minato et al. 1993).

Table 5 Effect of steam explosion on fermentation of oil palm frond (OPF) and oil palm empty fruit bunch (EFB)

\begin{tabular}{|c|c|c|c|c|c|c|c|c|}
\hline \multirow[t]{2}{*}{ Items } & \multicolumn{2}{|l|}{ OPF } & \multicolumn{2}{|l|}{ EFB } & \multirow[t]{2}{*}{ SEM } & \multicolumn{3}{|l|}{$\mathrm{P}$} \\
\hline & Control & Steam explosion & Control & Steam explosion & & S & $\mathrm{T}$ & $\mathrm{S} \times \mathrm{T}$ \\
\hline $\mathrm{pH}$ & 7.24 & 7.16 & 7.18 & 7.12 & 0.049 & 0.341 & 0.176 & 0.845 \\
\hline $\mathrm{NH}_{3}-\mathrm{N}(\mathrm{mg} / 100 \mathrm{~mL})$ & $20.36 b$ & $22.31 b$ & $27.66 \mathrm{a}$ & $25.34 \mathrm{a}$ & 0.852 & $<0.001$ & 0.829 & 0.037 \\
\hline TVFA (mmol/L) & $30.61 \mathrm{~b}$ & $35.96 \mathrm{a}$ & $28.72 b$ & $29.35 b$ & 1.503 & 0.022 & 0.082 & 0.155 \\
\hline \multicolumn{9}{|c|}{ VFA molar proportion (\%) } \\
\hline Acetate & $67.12 \mathrm{a}$ & $67.27 \mathrm{a}$ & $64.35 b$ & $65.71 \mathrm{ab}$ & 0.687 & 0.014 & 0.307 & 0.408 \\
\hline Propionate & $21.11 \mathrm{ab}$ & $20.66 \mathrm{ab}$ & $20.52 b$ & $21.59 \mathrm{a}$ & 0.322 & 0.616 & 0.358 & 0.046 \\
\hline Isobutyrate & $7.35 \mathrm{ab}$ & $7.58 \mathrm{ab}$ & $7.66 \mathrm{a}$ & $7.26 \mathrm{~b}$ & 0.113 & 0.966 & 0.471 & 0.022 \\
\hline Butyrate & $1.64 \mathrm{~b}$ & $1.63 \mathrm{~b}$ & $3.51 \mathrm{a}$ & $2.29 b$ & 0.370 & 0.009 & 0.135 & 0.143 \\
\hline Isovalerate & $0.72 \mathrm{a}$ & $0.78 \mathrm{a}$ & $0.80 \mathrm{a}$ & $0.68 b$ & 0.035 & 0.767 & 0.423 & 0.031 \\
\hline Valerate & $2.07 \mathrm{~b}$ & $2.08 \mathrm{~b}$ & $3.16 \mathrm{a}$ & $2.48 b$ & 0.163 & 0.002 & 0.074 & 0.064 \\
\hline$A: P$ & 3.18 & 3.26 & 3.14 & 3.05 & 0.072 & 0.119 & 0.924 & 0.282 \\
\hline
\end{tabular}

$\mathrm{S}$ represents the oil-palm by product, $\mathrm{T}$ represents steam explosion, and $\mathrm{S} \times \mathrm{T}$ represents the interaction effect between $\mathrm{S}$ and $\mathrm{T}$. In the same row, values with different letters represent significant differences $(P<0.05)$

TVFA total volatile fatty acids, $A: P$ molar ratio between acetate and propionate 
The surface morphology of all the samples performed by SEM indicate that steam explosion may damage cellulose, degrade hemicellulose, and reduce crystalline and amorphous cellulose, thereby favoring the adhesion of bacteria to the feed (Akin 1989; Benghedalia et al. 1993). Steam explosion could potentially promote the digestion and absorption of feedstuff in the rumen, thereby improving its nutritional value. At the same time, the cuticle structure of the feed particles is destroyed, and the contact areas between ruminal bacteria and feedstuff increase (Orpin 1984; Miron et al. 2001), thereby improving the accessibility to feedstuff.

In conclusion, steam explosion significantly affected the nutrient content of OPF and EFB. After steam explosion, NDF and ADF significantly decreased in OPF and EFB. Steam explosion significantly improved the predicted effective energy of OPF and EFB and increased gas production in vitro and VFA concentration.

Funding information This work was supported by grants from the National Key Research and Development Program of China (2018YFD0502300), the China Agricultural Research System (CARS37 ), and the Special Fund for Agro-scientific Research in the Public Interest (201503134).

\section{Compliance with ethical standards}

Conflict of interest The authors declare that they have no conflict of interest.

Open Access This article is distributed under the terms of the Creative Commons Attribution 4.0 International License (http:// creativecommons.org/licenses/by/4.0/), which permits unrestricted use, distribution, and reproduction in any medium, provided you give appropriate credit to the original author(s) and the source, provide a link to the Creative Commons license, and indicate if changes were made.

\section{References}

Abnisa, F., Arami-Niya, A., Daud, W.M.A.W., Sahu, J.N., and Noor, I.M., 2013. Utilization of oil palm tree residues to produce bio-oil and bio-char via pyrolysis, Energy Conversion and Management, 76, 1073-1082

Akin, D.E., 1989. Histological and Physical Factors Affecting Digestibility of Forages, Agronomy Journal, 81, 17-25

Benghedalia, D., Miron, J., and Solomon, R., 1993. The Degradation and Utilization of Structural Polysaccharides of Sorghum Straw by Defined Ruminal Bacteria, Animal Feed Science and Technology, 42, 283-295

Carvalheiro, F., Duarte, L. C., and Gírio, F. M., 2008. Hemicellulose biorefineries: a review on biomass pretreatments, Journal of Scientific \& Industrial Research, 67, 849-864

Carvalho, A. F. A., Marcondes W. F., Neto, P. O., Pastore, G. M., Saddler, J. N., and Arantes, V., 2018. The potential of tailoring the conditions of steam explosion to produce xylo-oligosaccharides from sugarcane bagasse, Bioresource Technology, 250, 221-229

Castro, F.B., Hotten, P.M., Orskov, E.R., and Rebeller, M., 1994. Inhibition of Rumen Microbes by Compounds Formed in the
Steam Treatment of Wheat-Straw, Bioresource Technology, 50, 25-30

Chaji, M., Mohammadabadi, T., Mamouei, M., and Tabatabaei, S., 2010. The Efect of Processing with High Steam and Sodium Hydroxide on Nutritive Value of Sugarcane Pith by in vitro Gas Production, Journal of Animal and Veterinary Advances, 9, 1015-1018

Chang, J., Cheng, W., Yin, Q.Q., Zuo, R.Y., Song, A.D., Zheng, Q.H., Wang, P., Wang, X., and Liu, J.X., 2012. Effect of steam explosion and microbial fermentation on cellulose and lignin degradation of corn stover, Bioresource Technology, 104, 587-592

Derakhshani, H., Tun, H.M., Cardoso, F.C., Plaizier, J.C., Khafipour, E., and Loor, J.J., 2017. Linking Peripartal Dynamics of Ruminal Microbiota to Dietary Changes and Production Parameters, Frontiers in Microbiology, 7,

Kim, W., Yahaya, M.S., and Goto, M., 2005. Effects of steam explosion on the chemical composition and rumen degradability of rice (Oryza sativa L.) straw, Grassland Science, 51, 139-144

Liu, J.X., and Orskov, E.R., 2000. Cellulase treatment of untreated and steam pre-treated rice straw - effect on in vitro fermentation characteristics, Animal Feed Science and Technology, 88, 189-200

Liu, J.X., Orskov, E.R., and Chen, X.B., 1999. Optimization of steam treatment as a method for upgrading rice straw as feeds, Animal Feed Science and Technology, 76, 345-357

Martin-Sampedro, R., Eugenio, M.E., and Villar, J.C., 2012. Effect of steam explosion and enzymatic pre-treatments on pulping and bleaching of Hesperaloe funifera, Bioresour Technol, 111, 460-467

Menke, K.H., Raab, L., Salewski, A., Steingass, H., Fritz, D., and Schneider, W., 1979. Estimation of the Digestibility and Metabolizable Energy Content of Ruminant Feedingstuffs from the Gas-Production When They Are Incubated with Rumen Liquor Invitro, Journal of Agricultural Science, 93, 217-222

Minato H, M.M., Cheng K J. , 1993. Attachment of microorganisms to solid substrates in the rumen. In: Genetics, Biochemistry and Ecology of Lignocellulose Degradation, (Ed. K. Shimada, Ohmiya, K., Kobayashi, Y., Hoshino, S., Sakka, K. And Karita, S.), Uni Publishers, Tokyo, 139-145

Miron, J., Ben-Ghedalia, D., and Morrison, M., 2001. Invited review: adhesion mechanisms of rumen cellulolytic bacteria, Journal of Dairy Science, 84, 1294-1309

Orpin, C.G., 1984. The Role of Ciliate Protozoa and Fungi in the Rumen Digestion of Plant-Cell Walls, Animal Feed Science and Technology, 10, 121-143

Orskov, E.R., and Mcdonald, I., 1979. Estimation of Protein Degradability in the Rumen from Incubation Measurements Weighted According to Rate of Passage, Journal of Agricultural Science, 92, 499-503

Sabiha-Hanim, S., Noor, M. A. M., and Rosma, A., 2015. Fractionation of oil palm frond hemicelluloses by water or alkaline impregnation and steam explosion, Carbohydrate Polymers, 115, 533-539

Silveira, M. H. L., Chandel A. K., Vanelli, B. A., Sacilotto, K. S., and Cardoso, E. B., 2018. Production of hemicellulosic sugars from sugarcane bagasse via steam explosion employing industrially feasible conditions: Pilot scale study, Bioresource Technology Reports, 3, 138-146

Tanpichai, S., Witayakran, S., and Boonmahitthisud, A., 2019. Study on structral and thermal properties of cellulose microfibers isolated from pinapple leaves using steam explosion, Journal of Environmental Chemical Engineering, 7, 1-7

Welkie, D.G., Stevenson, D.M., and Weimer, P.J., 2010. ARISA analysis of ruminal bacterial community dynamics in lactating dairy cows during the feeding cycle, Anaerobe, 16, 94-100

Publisher's note Springer Nature remains neutral with regard to jurisdictional claims in published maps and institutional affiliations. 